\title{
Transmissão da Tradição Umbandista: ou o Lampejo da Narração
}

\author{
Ana Clara Tomaz Carneiro* \\ Marilda Aparecida de Menezes**
}

\section{Resumo}

Este artigo se propõe a analisar a transmissibilidade da tradição umbandista pela oralidade, valorizando a memória e a experiência compartilhada na convivência cotidiana e nos rituais. A partir da etnografia realizada em uma tenda de umbanda, estabelecemos aproximações entre a transmissibilidade dos ensinamentos, rituais, princípios éticos e questões de identidade umbandistas, sob a perspectiva benjaminiana de experiência coletiva (erfahung), narração e tradição, utilizando os ensaios O Narrador (1985), Experiência e Pobreza (1985) e Teses sobre o Conceito de História (1985). Mobiliza-se, portanto, memória, narratividade e experiência.

Palavras-chave: Umbanda. Experiência. Memória. Transmissão. Narração. Tradição.

\section{Transmission Of The Umbandist Tradition: or the Flash of Narration}

\section{Abstract}

This article proposes to analyze the transmissibility of the Umbanda tradition through orality, valuing the memory and the shared experience in daily coexistence and rituals. From the ethnography carried out in an Umbanda tent, we established approximations between the transmissibility of Umbanda's teachings, rituals, ethical principles and identity issues, under the Benjamin perspective of collective experience (erfahung), narration and tradition, using the essays The Storyteller (1985), Experience and Poverty (1985) and Theses on the Philosophy of History (1985). Therefore, memory, narrativity and experience are mobilized.

Keywords: Umbanda. Experience. Memory. Transmission. Narration. Tradition.

* Universidade Federal do ABC. Mestranda no Programa de Pós-Graduação em Ciências Humanas e Sociais, formada no Bacharelado Interdiciplinar de Ciências e Humanidades, na UFABC. anaclaratomazcarneiro@gmail.com .

** Universidade Federal do ABC, Programa de Pós-Graduação em Ciências Humanas e Sociais. Professora Visitante Senior, UFABC, a partir de janeiro de 2017. Professora Visitante Nacional Senior (CAPES/PVNS) da Universidade Federal do ABC, 2012-2016. Pesquisadora do CNPq, nivel 1C. Professora aposentada da Universidade Federal de Campina Grande. menezesmarilda@gmail.com . 
110 Ana Clara Tomaz Carneiro

Marilda Aparecida de Menezes

\section{Transmisión de la Tradición Umbandista: $\mathrm{O}$ el Destello de la Narración}

\section{Resumen}

Este artículo propone analizar la transmisibilidad de la tradición de Umbanda a través de la oralidad, valorando la memoria y la experiencia compartida en la vida diaria y los rituales. A partir de la etnografía realizada en una tienda Umbanda, establecimos aproximaciones entre la transmisibilidad de las enseñanzas, los rituales, los principios éticos y las cuestiones de identidad de Umbanda, bajo la perspectiva de Benjamin de la experiencia colectiva (erfahung), la narración y la tradición, utilizando los ensayos $\mathrm{O}$ Narrador (1985), Experiencia y pobreza (1985) y Tesis sobre el concepto de historia (1985). Por lo tanto, la memoria, la narrativa y la experiencia se movilizan.

Palabras clave: Umbanda. Experiencia. Memoria. Transmisión. Narración. Tradicion.

\section{Introdução}

Os estudos de religião, sobretudo da Umbanda, se estabelecem em diferentes campos teóricos e por diversas temáticas. Nos interessa, contudo, evidenciar como se processa a transmissão daquilo que os umbandistas consideram Tradição de Umbanda.

Este artigo se propõe a analisar a transmissibilidade da tradição umbandista pela oralidade, valorizando a memória e a experiência compartilhadas na convivência cotidiana e nos rituais. Isso é feito ao estabelecer aproximações entre a transmissibilidade dos ensinamentos, rituais, princípios éticos e questões de identidade umbandista, sob a perspectiva benjaminiana de experiência coletiva (erfahung), narração e tradição, utilizando os ensaios O Narrador (1985), Experiência e Pobreza (1985) e Teses sobre o Conceito de História (1985). O estudo foi realizado a partir da etnografia em uma tenda de umbanda 1. Mobiliza-se, portanto, memória, narratividade e experiência.

Partiremos de uma discussão sobre umbanda e a transmissão pela oralidade, tanto em relação aos estudos sobre umbanda quanto sobre o que os umbandistas estudados na etnografia estabelecem como tradição. Com a intenção de aproximar as questões relativas à transmissão da tradição umbandista, à história e à memória, pensamos sobre a valorização da memória e da experiência transmitidas oralmente a partir do que entendemos como práticas, linguagens e símbolos. Sob perspectiva benjaminiana, aproximamos a dimensão do simbólico, do material, das interações sociais, das representações e dos valores transmitidos pelos membros da Tenda de Umbanda Estrela Matutina.

Esta pesquisa, baseia-se em estudo etnográfico empenhado na Tenda de Umbanda Estrela Matutina, localizada na cidade de Campinas-SP, ainda em realização. 
Com base no prefácio Walter Benjamin on a História Aberta, escrito por Jean Marie Gagnebin (2012, p.7-19), pretendemos realizar aproximações entre as condições de transmissão das experiências e as características da transmissibilidade da tradição umbandista interpretada na etnografia desempenhada até o momento. Segundo Gagnebin, tais experiências coletivas a serem transmitidas estão atreladas a uma temporalidade que marcam diversas gerações, evidenciando a manutenção da tradição passada ao identificar um universo de práticas e de linguagens comuns ao coletivo.

Assim como Concone (1987), acreditamos que toda tentativa de caracterização absoluta da Umbanda está fadada ao insucesso, podemos apenas refletir sobre características que são apresentadas em cada agrupamento, denominados de Tendas, Choupanas, Terreiros, Casas. Cabe, contudo, estabelecer que, mesmo não sendo uma religião uniforme, considerada heterogênea e nem um pouco hegemônica, há certo consenso de que a tradição transmitida nos espaços exclusivos para seus adeptos é dada de forma oral e reservada, de maneira a se perpetuar através da mobilização das memórias no presente.

Ainda que a definição de Umbanda seja um campo em disputa, nos atentaremos ao que os adeptos da Tenda de Umbanda Estrela Matutina compreendem sobre tradição umbandista, que, de certa forma, corrobora com aquilo que Rivas (2013) declara:

A umbanda tem como característica marcante a diversidade e pluralidade em suas manifestações, processo que não decorreu de cismas e rupturas. Essa característica é fruto de sua origem descentralizada, que possibilitou desde o início, a introdução de elementos regionais em sua rito-liturgia, mas sem perder a sua unidade, caracterizada na Vertente Una do Sagrado (Rivas Neto, 1996), marcando traços comuns às várias escolas em todos os tempos.

Sobre escolas umbandistas, Rivas Neto sustenta que:

Na Umbanda, pela diversidade dos seus adeptos, há também uma diversidade de ritos e de forma de transmissão do conhecimento. A essas várias formas de entendimento e vivência da umbanda denominamos escolas ou seguimentos. As várias escolas correspondem a visões, umas voltadas mais aos aspectos místicos e outras mais voltas à essência espiritual, abstrata. Embora não haja consenso quanto à ritualística, que são as várias formas de interpretar e manifestar a doutrina, a essência de todos é a mesma e todos são legitimamente denominados umbandistas (Rivas Neto, 2003, p. 459) 


\section{Ana Clara Tomaz Carneiro}

Marilda Aparecida de Menezes

É, sobretudo, a partir da valorização da unidade que se estrutura a tradição umbandista na Tenda de Umbanda Estrela Matutina, que se compromete em estabelecer ligações com sua própria trajetória, ou seja, com aqueles que possibilitaram a existência da tradição, o que envolve os processos de ritos de iniciação e a transmissão, de sacerdote para discípulo, de conhecimentos e práticas r umbandistas. Mobiliza, também, a essência da unidade enquanto filo-religião.

Para o entendimento de como a transmissibilidade da tradição é estabelecida na Tenda de Umbanda Estrela Matutina, se faz necessário conhecer algumas características desse agrupamento religioso. A Tenda de Umbanda Estrela Matutina, localizada na cidade de Campinas-SP, tem como sacerdote responsável (pai de santo) o Pai Medeiros, que, em suas falas, se referencia como pertencente à família espiritual do Pai Rivas Neto e Pai Matta e Silva. Essa corrente ou escola, como é chamada por Rivas Neto, é classificada como umbanda esotérica, mesmo que Pai Medeiros prefira não rotular a forma como se ritualiza em sua casa.

Sobre a Umbanda esotérica, Solera (2014) ressalta a importância de W.W da Matta e Silva como autor e sacerdote expoente, os quais trouxeram aos adeptos da Umbanda uma doutrina (epistemologia), uma linha de transmissão (método) e um modus vivendi (ética), com suas obras. Destacam uma forma de ritualizar e entender o sagrado a partir da lógica, dos estudos herméticos e dos fundamentos cabalísticos.

Solera (2014) descreve as contribuições de Matta e Silva, dando ênfase para a forma como o conhecimento sobre umbanda esotérica é transmitido e praticado. Ao descrever a doutrina da Umbanda esotérica como epistemologia e ao pensar a transmissão como método e o modus vivendi como ética, podemos estabelecer que o método é a transmissão pela oralidade e a ética umbandista é dada pela transmissão das experiências coletivas e pela valorização da memória.

Nesse sentido, observamos ações, disposições e manifestações nos rituais e a transmissão desses conhecimentos a partir dos ensaios de Benjamin (2014) que versam sobre experiência, narração e história.

\section{Tradição oral umbandista: a ancestralidade, o tempo e a memória}

Muito se diz sobre as características da oralidade na Umbanda enquanto uma das escolas pertencentes às, comumente chamadas, religiões afro- 
brasileiras. Tal característica se apresenta por estabelecer um testemunho oral, o qual transmite conhecimento de uma geração para a seguinte com base na tradição.

Consideramos que o uso do termo "tradição" é muito bem-vindo, por permitir aproximações entre o que os membros da Tenda de Umbanda Estrela Matutina consideram e reproduzem com as questões elaboradas por Benjamin (2012). O autor trabalha com o entendimento sobre a tradição a partir das experiências coletivas comunicáveis, plenas de sentido, construídas por um tempo outro, muito diferente do tempo moderno.

Segundo Carneiro e Rivas (2012), as religiões afro-brasileiras calcam sua teologia na tradição oral, não por se tratar de falta de habilidade ou desconhecimento tecnológico, mas há, na verdade, uma escolha pelo método.

Antes de nos aprofundarmos nas motivações que levam o método oral a ser privilegiado na transmissão e na perpetuação da umbanda, gostaríamos de deixar registrado que dentro da Tenda de Umbanda Estrela Matutina há a preocupação em estabelecer a umbanda, em sua realidade, a partir de influências não apenas afrocentradas, mas incorporando outras influências, tais como ameríndias, orientais e européias de forma democrática e manifestando a universalidade. Dentro da $\mathrm{TUEM}^{2}$ há a perspectiva fundamental de que a Umbanda, ou, como define Pai Medeiros, O Movimento Umbandista, busca restabelecer a Tradição de Síntese, que faz uma conexão direta e imediata com o Sagrado, o conhecimento-uno, o amor e a sabedoria cósmica. Segundo a cosmovisão adotada na TUEM, procura-se o resgate da religiovera, a religião primeva, na qual todas as religiões, filosofias, artes e ciências convergem. Essa visão é parte constituinte da identidade e da ritualística deste grupo umbandista, herdada de Pai Rivas Neto, o qual iniciou Pai Medeiros, sendo representante herdeiro dos ensinamentos da umbanda esotérica, advindos de Matta e Silva.

Na perspectiva de Carneiro e Rivas (2012), o método da oralidade adotado pela tradição de Umbanda e as religiões afro-brasileiras se estabelece a partir de ressignificações. Nesse sentido, diferencia-se dos métodos intrínsecos às religiões ocidentais, as quais os autores classificam como herdeiras das religiões abrâmicas, que se estabelecem fundamentalmente pela escrita.

Dentre os fatores que permitem a valorização do método oral e que se distanciam das religiões ocidentais, encontra-se a vertente una do sagrado.

Tenda de Umbanda Estrela Matutina 


\section{Ana Clara Tomaz Carneiro}

Marilda Aparecida de Menezes

É a partir dessa perspectiva que a tradição umbandista vive o sagrado ao se conectar com o sobrenatural e com o transcendental, ainda que manifestados no mundo físico. Ass diferenças entre os ritos são tão expressivas e diversas que por vezes poderia ser questionado se cabem todos na mesma categoria religiosa. Ainda assim, há pontos fundantes que são comuns a todas as religiões afro-brasileiras encontradas no que Rivas Neto (2003) demonstra como vertente una do sagrado ${ }^{3}$ (Carneiro e Rivas, 2012).

Essa percepção do sagrado propõe que os ritos não apresentam características e dogmas pré-estabelecidos, mas se estabelecem a partir de um eixo baseado nessa cosmovisão, em que a possibilidade de ressignificações e adaptações temporais-espaciais sejam compreendidas a partir da ritualística da tradição oral dadas pelas narrativas que atravessam várias gerações.

Outra característica importante se relaciona ao tempo. O tempo é construído a cada contexto, a cada necessidade, depende do ângulo da iniciação que se estabelece no processo de transmissão partilhado com a comunidade. Há um compartilhamento da experiência religiosa transcendente de forma coletiva. O tempo, como coloca Carneiro e Rivas (2012), tem amplos pontos de referências, bem como as experiências individuais e as coletivas.

A diferenciação basilar entre a tradição oral em relação à tradição escrita é que na tradição escrita o tempo é linear e tem um marco inicial, já nas religiões de tradição oral o tempo é circular e não há a percepção de "passado, presente e futuro" de forma sequencial.

Segundo Silva e Silva (2005), são duas as principais percepções filosóficas sobre o tempo: o tempo cíclico e o tempo linear. Na percepção do tempo linear, predominante no Ocidente, a construção histórica e narrativa tem um começo, meio e fim, que, invariavelmente, se postula de forma única (um único início para o mundo, história, universo e um único final). Aqui se encontra a visão progressista incorporada pelo iluminismo e cristalizada pela modernidade, que ainda influencia o Ocidente. Por outro lado, para a percepção de tempo cíclico há sempre um recomeço.

Essa característica do tempo cíclico foi possível observar em uma das falas de Pai Medeiros, bem como nos diversos ritos observados durante nosso trabalho etnográfico realizado em 2019. Em um dos ritos realizados internamente para os filhos da Tenda de Umbanda Estrela Matutina, Pai Medeiros, em suas palavras iniciais sobre o rito que estava para começar, se prolonga ao conferir a importância deste rito.

Tal vertente é baseada em uma ligação entre a Divindade, Potestade, Ancestrais e a Humanidade, não cabendo a esse artigo esmiuçar tal concepção religiosa. 
Em sua fala, Pai Medeiros diz que o rito que estava sendo iniciado teve como início o rito anterior, ocorrido quinze dias antes, demonstrando a circularidade do tempo. O rito que se encerra dá origem ao próximo rito, e assim por diante. $\mathrm{Na}$ construção do rito não há, de fato, um final, mesmo que aparentemente já não tenha a presença dos seres espirituais incorporados, nas diversas roupagens fluídicas ${ }^{4}$, aquilo que foi "girado" não acaba naquele momento, não acaba quando a Tenda fecha.

É interessante o uso da palavra "gira" para designar o rito. O uso do termo remete ao círculo, aquilo em que há uma rotação há também um ciclo. Ainda que as formas que se dão os ritos aparentem uma linearidade, pois se organizam em começo, meio e fim visivelmente falando, na realidade há em todo rito um recomeço e uma oportunidade de renovar os pedidos e as intenções daqueles que são beneficiados por ele.

Pai Medeiros reforça que o rito ou a "gira" de umbanda reconstitui o processo da vida. Em seus processos ritualísticos há a representação da gestação da gira, marcada pelo rito nomeado de propiciatório, o nascimento da gira, quando há a incorporação ${ }^{5}$ das entidades, ${ }^{6}$ e o desencarne, quando se encerra o rito após a partida das entidades ${ }^{7}$. Esse processo sempre tem um recomeço, assim como a vida nos princípios teológicos umbandistas tem um recomeço pela oportunidade das reencarnações. Ainda que aparente o mesmo ciclo, os ritos, semelhantemente a nova encarnação, possibilitam novas oportunidades, de maneira que não é possível haver reproduções idênticas. Cada rito é único pelo o que ocorre durante a realização, pelas influências presentes e por todas as ressignificações mobilizadas.

Há, ainda, a esfera do entendimento da não existência de um marco inicial na umbanda. Assim, concordamos com Rohde (2011) ao dizer que a forma de existência promovida pela umbanda rompe com a ideia de uma construção pontual e processual no tempo, é pela não aceitação de um marco

\footnotetext{
4 Roupagens fluídicas é o termo usado para caracterizar as diferenças em que os seres espirituais que incorporam se apresentam. Na TUEM são quatro as roupagens fluídicas: crianças - representando o início e o amor; caboclos e caboclas - representam a juventude e a atividade; pais e mães- velhas - representam a velhice e a sabedoria; exu - representam a transição, na relação do ciclo da vida é aquele que liga a morte e o nascimento.

5 Incorporação segundo a tradição umbandista é uma mecânica, uma forma, de mediunidade e de atividade mediunizada pelas entidades.

6 Entidade tem o mesmo significado de seres espirituais que incorporam nos ritos

7 Ao utilizar partida das entidades referimos ao processo de desincorporação, ou fim do transe mediúnico dado pela incorporação.
} 


\section{Ana Clara Tomaz Carneiro \\ Marilda Aparecida de Menezes}

de origem único que ela estabelece uma das suas principais características: ser universalista. Há, nesse sentido, uma formação multicultural e uma característica policêntrica que possibilitaram o surgimento descentralizado das diversas escolas umbandistas.

Voltando às características que justificam a escolha da oralidade como método para a transmissão e perpetuação da tradição umbandista, há a valorização da memória. Na tradição oral ela é evocada pelos rituais, é dentro da raiz ${ }^{8}$ da casa que o sacerdote transmite aos seus filhos espirituais os conhecimentos, os quais são aprendidos e mobilizados pela memória e pelas experiências.

Como já havíamos comentado, no que se refere aos ritos da tradição umbandista, de forma geral, evoca-se a partir das experiências transmitidas pelos ensinamentos passados oralmente. $\mathrm{Na}$ rotina dos ritos e da convivência em grupo destaca-se como fonte de perpetuação desses ritos a própria memória do grupo, do Sacerdote e daquilo que foi vivido ou transmitido para o mesmo. Encontra-se, então, uma relação entre a formação da memória individual e da memória coletiva. Sobre isso Halbwachs (2012) aponta que as lembranças podem, a partir dessa vivência, ser reconstruídas ou simuladas, também podendo criar representações do passado assentadas na percepção de outras pessoas, no que imagina ter acontecido ou na internalização de representações de uma memória histórica.

Ainda na perspectiva de Halbwachs (2012), consideramos a ideia de memória coletiva como aquela que se refere à memória compartilhada em alguns eventos particulares (Cordeiro, 2015). Ela é composta de memórias individuais convergentes e se solidifica como uma massa de recordações comuns que ganha consistência à medida que seus membros a rememoram com mais vigor e constância, sendo que, para isso, precisam estar cada vez mais coesos, isto é, cada vez mais alinhados a uma corrente de pensamento coletivo comum, como se ensina dentro da tradição umbandista esposada pela Tenda de Umbanda Estrela Matutina.

No que tange às ressignificações e ao movimento cíclico, encontramos em Halbwachs (2012) contribuição importante no campo da memória religiosa, em que as tradições são fruto de reconstruções geradas pelas necessidades do presente, demonstrando a importância dos lugares físicos reais para que se possa fixar uma tradição. Desta forma, para um grupo

$8 \quad$ Raiz é outro termo utilizado para designar as escolas umbandistas. 
religioso, o exercício de memória se apoia em formas concretas dos acontecimentos, das pessoas e dos lugares que podem ser modificados de acordo com a necessidade e as características ligadas ao grupo e à escola umbandista em que se enquadra.

Há, nesse contexto, relações entre tempo e espaço que são férteis para a transmissibilidade da tradição, a qual é conduzida pelas experiências e pela memória. Destacamos que tal experiência é aquela que Benjamin (2012) define como experiência coletiva, a qual o filósofo discute em seus ensaios O Narrador e Experiência e Pobreza. Para ele, a arte de narrar e de transmitir conhecimento de pessoa para pessoa estava em declínio em decorrência da modernidade capitalista, visto que a experiência coletiva (erfabung) se enfraquecia e abria espaço para a experiência vivida (erlebniz).

No que se refere a memória, Gagnebin (2012) caracteriza a importância da dimensão da abertura, encontrada na obra de Benjamin. Segundo a autora, a memória é decisiva na arte de narrar e é fundamental para a transmissão de experiências coletivas, contexto em que a dinâmica ilimitada da memória também constitui narração. Assim, a autora afirma que "cada história é o anseio de uma nova história, que desencadeia uma outra, que traz uma quarta" (GAGNEBIN, 2012, p. 13).

Gagnebin completa ainda que, com a mudança encontrada na modernidade, o tempo se torna uma grandeza econômica. Dessa forma, poupar tempo é, de certa forma, lucrar economicamente. Nesse processo, a memória se transforma. As mudanças no modo de produção modificam a vida, principalmente o modo de narrar, contar, escutar, lembrar e aprender (GAGNEBIN, 2014, p. 221).

O desenvolvimento técnico capitalista contemporâneo torna ilusória qualquer esperança de retorno a essas formas comunitárias de vida, lembrança e narração, que são facilmente idealizadas em retrospecto. Ao contrário: para lutar contra esse encurtamento da percepção temporal, contra essa espécie de narcisismo do presente, que corre atrás de novidades rapidamente caducas segundo a lei do consumo de mercadorias novas, deve-se inventar outras formas de memória e de narração, capazes de sustentar uma relação crítica com a transmissão do passado, com o lembrar, e com a construção do futuro e o esperar (2014, p. 221).

Nesse sentido, observamos na transmissibilidade da tradição umbandista a possibilidade de uma outra forma de memória e de narração, 
estabelecida de maneira aberta. Ela transforma o passado, pois assume uma forma nova que poderia ter desaparecido no esquecimento; ela transforma o futuro, pois ele se revela como a realização possível das promessas do passado, podendo ser perdidas se não forem inscritas no tempo atual.

A partir dessa perspectiva, pensamos e nos inserimos nos ritos umbandistas realizados na TUEM, em que as ressignificações são compreendidas desde as concepções teológicas da umbanda, passam por toda a memória evocada pelo sacerdote e a tradição esposada, envolvendo as memórias e afetos particulares daqueles que frequentam a TUEM e também de ambas as pesquisadoras.

\section{Transmissão da tradição umbandista ou o lampejo da narração}

Com a intenção de identificar a transmissibilidade da tradição umbandista dentro da Tenda de Umbanda Estrela Matutina, e pensar sobre as trocas e a importância da memória nos rituais desempenhados nessa coletividade, a partir do método etnográfico, observamos a valorização da transmissibilidade dada pela experiência. Considerando os aspectos da etnografia, fizemos parte dos rituais nos apoiando nas teorias da antropologia dos afetos. Buscamos evocar elementos da etnografia com base nas circunstâncias com que os afetos e a intersubjetividade estão presentes nos relatos etnográficos, uma vez que consideramos que não seja possível separar as narrativas das afetividades que as constroem (FAVRET-SAADA, 2001).

As impressões a serem descritas a seguir favoreceram as aproximações com os pressupostos e as características da experiência que Benjamin aborda nos ensaios $O$ Narrador e Experiência e Pobreza. Ele destaca que são cada vez mais raras as pessoas que conseguem elaborar uma narrativa. Estamos privados de uma faculdade que parecia natural e inalienável: a faculdade de intercambiar experiências. Esse fenômeno é causado por aquilo que o autor caracteriza como pobreza da experiência, uma vez que "as ações da experiência estão em baixa" (BENJAMIN, 2012, p.213).

Diante disso, observamos aproximações entre aquilo que se considera como tradição umbandista e as condições da realização da transmissão de experiências, como propõe Gagnebin (2012). Segundo a autora, as características necessárias para que a narração seja preservada da maneira como Benjamin especificou em sua teoria são definidas pela comunidade de vida e discurso, ligadas a um trabalho e a um tempo partilhados, ou seja tradição e memória. Dentre as condições encontra-se a necessidade de que a 
experiência transmitida pelo relato deve ser comum ao narrador e ao ouvinte, pressupõe-se, portanto, uma comunidade de vida, de crenças e de discursos.

Outra condição para a transmissão de experiências é o entendimento do tempo de forma mais global, em que a atividade narradora se faz presente por uma questão de compatibilidade e compartilhamento do tempo ligado à tradição. Também se encontra na memória a importância para que a experiência seja transmitida (GAGNEBIN, 2012, p.11).

Corroboramos com a perspectiva de que a narração faz convergir a história passada e a história presente, movimento marcado pela memória. A narração se torna consciência do presente que não se orienta pela progressismo do tempo. Desta forma, para ser assimilada exige tanto do ouvinte quanto do narrador entrega e dedicação, sem interferências da pressa ou da intenção, ou seja, ambos devem saber acolher ritualisticamente os saberes que o antecedem (PEREIRA, 2006).

Para pensarmos sobre a transmissão da tradição umbandista realizada no coletivo estudado, propusemos um recorte dos estudos etnográficos. Apresentaremos nesse artigo parte das inquietações encontradas, especificamente a valorização daquilo que foi transmitido pelos ancestrais.

Um dos ritos realizados no ano de 2019, direcionado apenas aos pertencentes da corrente ${ }^{9}$, seguiu o roteiro comum àqueles ritos, ou seja, uma estrutura com começo, meio e fim. No início do rito todos os médiuns se posicionaram dentro do congá ${ }^{10}$. Em um primeiro momento entoou-se os pontos cantados ${ }^{11}$ que retomam a ancestralidade da casa, que significam pontos cantados em referência aos mentores espirituais ${ }^{12}$ que fundaram a história da tradição umbandista entendida na TUEM. Cantou-se primeiro para Pai Guiné, mentor espiritual que se manifestava como pai-velho incorporado no médium Matta e Silva, conhecido como Mestre Yapacani, propulsor da Umbanda esotérica. Em seguida cantou-se o ponto de Caboclo

9 Corrente é o termo usado internamente para designar aqueles que pertencem à comunidade da casa, ou seja, são os médiuns considerados "filhos de santo".

10 Congá é o termo usado internamente para designar o espaço diferenciado onde se realiza os rituais de umbanda, o congá da TUEM tem seu chão coberto por areia.

11 Pontos cantados são preces ou orações musicadas, tem seu próprio modo e métrica musical, trazem mensagens sobre amor, sabedoria e felicidade, há pontos cantados para todas as entidades que trabalham no terreiro de umbanda. Tais pontos servem para auxiliar nos ritos, muitas vezes direcionando o andamento e o ritmo dos trabalhos.

12 Também conhecidas como entidades ou guias. Dentro do conhecimento umbandista são espíritos altamente iluminados que através da mediunidade se fazem presentes transmitindo mensagens de amor e sabedoria, propondo direcionamentos para a comunidade. 
das 7 Espadas e o ponto de Caboclo Urubatão da Guia, ambos mentores espirituais mediunizados por Pai Rivas, conhecido como Mestre Arapiaga. Mestre Arapiaga foi iniciado, ou seja, obteve conhecimentos e práticas sobre umbanda, depois de anos de convivência com Mestre Yapacani. Esse, por sua vez, iniciou Pai Medeiros, Sacerdote responsável pela TUEM, conhecido como Mestre Karabayara. Por último cantou-se para Caboclo Arranca Toco, mentor espiritual responsável pela coletividade da Tenda de Umbanda Estrela Matutina, mediunizado por Pai Medeiros.

Apenas esse processo descrito já bastaria para entendermos a importância e a valorização da ancestralidade, daqueles que transmitiram conhecimentos e práticas usuais na TUEM. Quanto à ancestralidade e à denominação "família de santo" adotada por Lima (1977) a partir da referência popular corrente entre os adeptos das religiões afro-brasileiras, decidimos utilizar essa mesma expressão, pensando nas definições e no conjunto dos aspectos classificatórios do "parentesco de santo"; nos papeis sociais dos pais e avós de santo; no relacionamento com filhos, netos de santo; nos demais descendentes e em todo o grupo familiar que se unem na religião. Para o autor, entre os aspectos passíveis de análise da família de santo está a solidariedade grupal, a autoridade dos pais de santo e todos os aspectos estruturais e funcionais do grupo.

Um dos principais amálgamas dessa diversidade é a ancestralidade. Para seus integrantes, ela é responsável pela visão de passado e pela possibilidade de continuidade no futuro. O sentido da ancestralidade se encontra no plano da descendência religiosa, como demonstrado na TUEM, que tem suas relações imbricadas num misto de respeito à ancestralidade, à forma como se opera a memória religiosa umbandista, bem como se ritualiza umbanda.

É essa valorização da ancestralidade que se encontra na TUEM, característica fundamental para a existência de narradores, pois é desta forma que a transmissão das experiências produz as relações de geração para geração. Para entender isso podemos usar a parábola do velho em seu leito de morte que revela aos filhos a existência de um tesouro oculto nos vinhedos, os filhos cavam, mas não descobrem vestígios do tesouro. Não percebem, pois que com a chegada do outono as vinhas produzem mais que qualquer outra na região.

Esta pequena narrativa expressa um sentido sábio. O que foi transmitido, em verdade, foi nada menos que uma certa experiência: a compreensão de que a felicidade não está no ouro a ser encontrado, mas no 
trabalho propriamente dito. Segundo Benjamin, experiências como esta foram transmitidas de geração a geração (BENJAMIN, 2012, p.123).

Há, nessa valorização da ancestralidade pressupostos que Gagnebin (2007) destaca como importantes para entender a experiência coletiva (erfahrung), visto que a experiência se inscreve em uma temporalidade comum a várias gerações, em que a tradição seja compartilhada.

Dando continuidade ao rito que estávamos descrevendo, logo após os pontos cantados, o sacerdote, no caso Pai Medeiros, adentra ao congá, seguindo ainda a estrutura desse rito, realiza uma oração, pedindo proteção ao mundo espiritual e que proporcione e concretize boas vibrações para os trabalhos daquela noite, mais uma vez invocando a ancestralidade. Em seguida é feita a prédica, a qual, segundo Pai Medeiros, é feita para direcionar os pensamentos e sentimentos daqueles que estão ali, a fim de se comunicar mais facilmente com o plano espiritual. Essas prédicas são, em sua maioria, uma conversa, alguns minutos para falar sobre algum assunto que seja caro aos umbandistas, desde assuntos relacionados à mediunidade, comportamento, ritualização, entre outros. Nessa prédica em específico, Pai Medeiros procurou falar sobre seu processo de iniciação na Umbanda juntamente com seu pai, Mestre Arapiaga.

Conta que durante seus anos junto a Mestre Arapiaga esteve em diversas funções, fez diversos preceitos, sempre quis estar mais perto de Pai. Muito foi apreendido e muito está em sua memória, principalmente devido à prática e ao trabalho realizado. Sua fala se concentra em dar importância ao seu Mestre, das poucas e boas conversas que tiveram e das vezes que Mestre Arapiaga falava de Mestre Yapacani. Dizia Pai Medeiros que Mestre Arapiaga falava muito sobre Mestre Yapacani, tanto que parecia que o conhecia apenas de ouvir sobre suas histórias, sobre sua figura como Mestre, sobre seus feitos e sua ética como expoente do movimento umbandista.

Pai Medeiros, que ouvia seu pai (Mestre Arapiaga) falar sobre as areias sagradas da Tenda de Umbanda Oriental, diz que hoje, quando pisa nas areias sagradas da Tenda de Umbanda Estrela Matutina, é como se pisasse nas areias sagradas da Ordem Iniciática do Cruzeiro Divino, casa de Mestre Arapiaga, que, por sua vez, são as mesmas da Tenda de Umbanda Oriental, casa que tinha o comando de Mestre Yapacani, pois representa a tradição que não muda.

É a partir dessa fala de Pai Medeiros que podemos observar as características que Gagnebin (2012) indica serem necessárias para que a narração seja preservada de acordo com a teoria da narração em Benjamin. São elas: a comunidade de vida e discurso; trabalho e tempo partilhados; tradição e memória comuns. 
Marilda Aparecida de Menezes

É possível identificar uma comunidade de vida e discurso quando Pai Medeiros fala sobre sua experiência durante os anos de iniciação junto de seu mestre, ao destacar as diversas funções, as poucas conversas que tinham, as vezes que ouvia de seu mestre sobre Mestre Yapacani. Isso possibilita perceber uma comunidade de vida e de discurso, pois, o que Pai Medeiros compartilhou com seus mestres em sua trajetória de iniciação, todos os médiuns ali presentes também compartilham com o Pai Medeiros. Essa comunidade de vida e discurso é marcada pelo tempo dedicado ao fazer umbandista, bem como pelo compartilhamento de um entendimento do que é a tradição umbandista e sua ritualização.

Ao se referir ao tempo em que esteve junto de seu mestre, Pai Medeiros destaca outra questão importante dentro da tradição umbandista, é necessário tempo para o processo de iniciação, e esse o tempo permeia de formas diferentes. Lembramos de algumas vezes em que Pai Medeiros destaca que um iniciado na umbanda precisa de no mínimo quatorze anos para adentrar os mistérios da umbanda e que um rito de umbanda equivale a dez anos de trabalho.

Ao referenciar as areias da Tenda de Umbanda Estrela Matutina como as mesmas de seus ancestrais, podemos identificar uma memória e tradição comuns, tanto em relação ao próprio Pai Medeiros, como em relação àqueles que estavam presentes, seus filhos de santo. Há, portanto, uma experiência coletiva, algo que pode ser transmitido.

Também é imperativa a importância da oralidade para se transmitir a tradição umbandista, visto que mesmo nos livros sobre umbanda nada se encontra sobre como ritualizar, ou, como Pai Medeiros prefere nomear, não se encontra os fundamentos da umbanda em obras escritas.

Ainda sobre a ritualística na umbanda, há a dimensão das diferentes formas de ritualizar, como já discutimos no que tange à diversidade das escolas umbandistas. Cabe também comentarmos que se na transmissão da tradição pela evocação de memórias há o interesse em conservar o que foi narrado, possibilitando uma dimensão da narração como forma artesanal de comunicação, sem se preocupar em ser um relatório ou um informativo. Há, em cada narração, o mergulho na vida do narrador para, em seguida, tirá-la dele. Assim, imprime-se a marca do narrador na oralidade, como a mão do oleiro na argila (BENJAMIN, 2012, p. 221).

É possível identificar o lampejo da narração na transmissão da tradição umbandista pelas características acima abordadas, mas também por apresentar 
características que destacam a convergência da história passada com a história presente: ela se torna consciência do presente que não se orienta por uma concepção de tempo progressivo, mas intensivo, das experiências compartilhadas e dos significados atribuídos à elas. Para ser assimilada exige de seu ouvinte e de seu narrador entrega e dedicação, sem pressa e sem intenção.

Há na transmissão da tradição umbandista como processo ritualístico e como parte da iniciação de adeptos a valorização da memória dos ancestrais, a valorização do trabalho comum e experiências partilhadas pela prática umbandista. Tais aspectos correspondem com o que discutimos em relação à narratividade em Benjamin (2012).

Destaca-se a designação dos pais de santo como Mestres, o que podemos relacionar com a figura do mestre que Benjamin (2012) destaca como aquele que sabe dar conselhos e sabedoria-conhecimento em casos diversos, pois este recorre ao acervo de toda uma vida, que não inclui apenas a própria experiência, mas em grande parte também a experiência alheia, que infunde seu íntimo naquilo que tem conhecimento por ouvir dizer.

A seguir, reproduzimos um ponto cantado no mesmo dia que relatamos anteriormente:

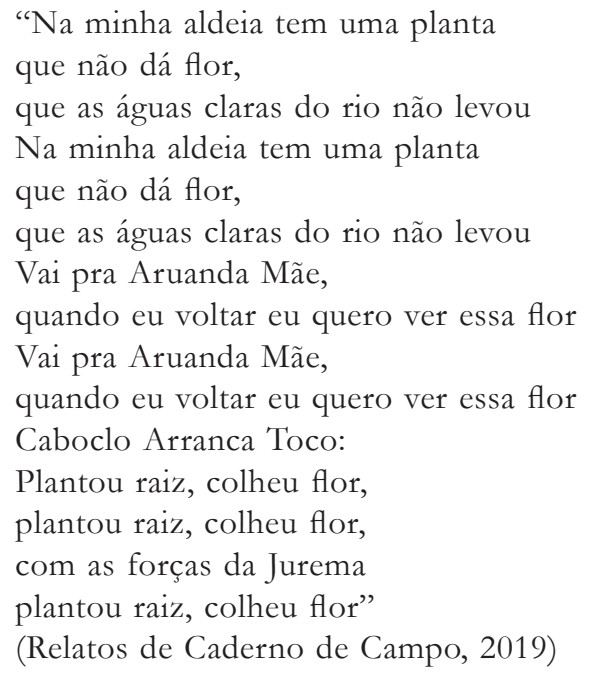

Essa canção traz alguns elementos interessantes para os propósitos deste trabalho. Em "plantou raiz colheu flor" podemos interpretar que "plantar raiz" significa transmitir os ensinamentos e experiências da tradição, 


\section{Ana Clara Tomaz Carneiro}

Marilda Aparecida de Menezes

os quais, como exemplificado anteriormente, se constitui pelo contato do umbandista com seu Mestre (Mestre Arapiaga) e que este, por sua vez, teve seus conhecimentos da tradição transmitidos por seu Mestre (Mestre Yapacani). Assim, "plantar raiz" é propriamente a transmissão da tradição, a concretização das memórias coletivas de forma ritualizada para que sejam passadas de geração a geração, formando a comunidade de experiências coletivizadas. Nessa perspectiva, a expressão "colheu flor" pode ser interpretada como a crença em que ao transmitir a tradição ela pode ser colocada em prática e despertar em outras coletividades o que é desperto dentro da TUEM. Assim, essa tradição tem potencialidade de ser compartilhada outras vezes e as experiências podem ser ouvidas e narradas como herança (BENJAMIN, 2012, p. 123).

Nesse sentido, trazendo à luz o texto Teses Sobre o Conceito de História (BENJAMIN, 2012), observamos pontos convergentes entre a força germinativa e a perspectiva da obra aberta:

Mesma preocupação de salvar o passado no presente graças à percepção de uma semelhança que os transforma a ambos: transforma o passado porque este assume uma forma nova, que poderia ter desaparecido no esquecimento; transforma o presente porque este se revela como sendo a realização possível dessa promessa anterior, que poderia ter-se perdido para sempre, que ainda pode se perder se não a descobrirmos, inscritas na linha do atual (GAGNEBIN, 2012, p. 16).

É possível afirmar, assim, que o ponto cantado remete à ideia de que a narrativa tem uma força germinativa (BENJAMIN, 2012), "pois assemelhase às sementes de trigo que durante milhares de anos ficaram fechadas hermeticamente nas câmaras das pirâmides" (BENJAMIN, 2012; p. 220). Essa passagem expressa de forma poética a ideia da narração, assim como o faz o ponto cantado que analisamos.

Fazendo um comparativo, pretende-se recuperar na imagem da planta o percurso de seu desenvolvimento até que vire flor. Essa ideia é encontrada, de maneira mais enfática, em Teses sobre o conceito de história que afirma que o que resulta da narração é a experiência. Sendo assim, a experiência é, por sua vez, o prolongamento da narração. Indica-se o lugar propício para que surtam resultados, que não poderia ser outro o terreno próprio para cultivo da experiência se não a memória. 


\section{Algumas considerações}

Ao destacar a importância da memória como terreno para a narração, sendo essa a forma da transmissão da tradição umbandista, podemos entender que há uma dimensão dessa transmissão em que não há uma forma, ou mesmo um guia. Tal movimento permite que haja diversas formas de ritualizar a tradição umbandista, mesmo que todos valorizem a ancestralidade, nenhum rito é igual ao outro. Nesse sentido, os ritos realizados por Pai Medeiros não são iguais aos ritos realizados por Pai Rivas, mesmo que Pai Rivas tenha iniciado e transmitido suas experiências para Pai Medeiros, pois há as marcas do narrador, no caso o Pai de Santo.

É nessa perspectiva de que há uma abertura para ressignificações dadas pela transmissão e pela memória que aproximamos com o que Pai Medeiros fala sobre a tradição umbandista: "a constante da Tradição Umbandista é a contínua mudança”.

Por fim, podemos descrever que a forma de transmissão da tradição umbandista, valorizada pela oralidade, se estabelece em um tempo diferenciado, pois assume formas de trabalho compartilhados, marcadas principalmente pela prática, evidenciando uma experiência coletiva, que só é passível de transmissão quando se ancora em uma tradição e em uma memória compartilhadas. Desta forma, temos base para que haja, mesmo como lampejo, ainda no mundo contemporâneo, uma prática de narratividade a qual Benjamin (2012) percebe como não mais presentes.

Podemos identificar o Pai de Santo/Sacerdote de Umbanda como narrador, aquele que ainda possui a capacidade inalienável de narrar as experiências coletivas, essa potencialidade contribui para pensarmos que não há extinção da arte de narrar, ou seja, o compartilhamento das experiências coletivas se faz presente nas diversas escolas umbandistas, sendo essa a forma de transmissão de seus valores, éticas, costumes e rituais.

\section{Referências}

BENJAMIN, Walter. Experiência e pobreza. In: Obras escolhidas. Magia e técnica, arte e política: ensaios sobre literatura e história da cultura. São Paulo: Ed. Brasiliense, 2012. v. 1.

BENJAMIN, Walter. O narrador: considerações sobre a obra de Nikolai Leskov. In: Obras escolhidas. Magia e técnica, arte e política: ensaios sobre literatura e história da cultura. São Paulo: Ed. Brasiliense, 2012. v. 1.

BENJAMIN, Walter. Sobre o conceito de História. In: Obras escolhidas. Magia e técnica, arte e política: ensaios sobre literatura e história da cultura. São Paulo: Ed. Brasiliense, 2012. v. 1. 
126 Ana Clara Tomaz Carneiro

Marilda Aparecida de Menezes

CONCONE, Maria Helena. Umbanda, Uma Religião Brasileira. 1. ed. São Paulo: CER/ USP, EDUSP, 1987.

CARNEIRO, João Luiz; RIVAS, Maria Elise. Teologia Da Tradição Oral: Uma

Questão Para As Religiões Afro-Brasileiras: Uma Questão Para As Religiões Afro-

Brasileiras. Revista Pistis Praxis, v. 4, n. 2, p. 609-624, 2012.

FAVRET-SAADA, Jeanne. 2005. Ser afetado. Cadernos de Campo n.13. p.155-161.

FAVRET-SAADA, Jeanne. 2011. Le mots, la mort, les sorts. Paris: Gallimard.

GAGNEBIN, Jeanne Marie. Prefácio. In: BENJAMIN, Walter. Obras escolhidas. Magia

e técnica, arte e política: ensaios sobre literatura e história da cultura. São Paulo: Editora Brasiliense, 2012. v. 1.

GAGNEBIN, Jeanne Marie. Lembrar escrever esquecer. São Paulo: Editora 34, 2006.

GAGNEBIN, Jeanne Marie. História e narração em Walter Benjamin. São Paulo:

Perspectiva, 2007.

GAGNEBIN, Jeanne Marie. Limiar, aura e rememoração: ensaios sobre Walter Benjamin. São Paulo: Ed. 34, 2014.

GOLDMAN, Márcio. Os tambores dos mortos e os tambores dos vivos. Etnografia, antropologia e política em Ilhéus, Bahia. Revista de Antropologia (46) 2. Brasil, 2003.

LIMA. Vivaldo da Costa. A família de santo nos candomblés jejes-nagôs da Bahia. $1^{\circ}$ edição UFBA, Bahia, 1977.

PEREIRA, Marcelo de Andrade. O lugar do tempo: experiência e tradição em Walter Benjamin. Dissertação (Mestrado em Filosofia) - Faculdade de Filosofia e Ciências Humanas da Universidade Federal do Rio Grande do Sul. Porto Alegre, 2006.

RIVAS, Maria Elise Gabriele Baggio Machado. O mito de origem: uma revisão do ethos umbandista no discurso histórico. São Paulo: Arché, 2013.

RIVAS NETO, Francisco. Sacerdote, mago e médico: cura e autocura umbandista. São Paulo: Ícone, 2003.

ROHDE, Bruno Faria. A umbanda tem fundamento, e é preciso preparar: abertura e movimento no universo umbandista. Dissertação (Mestrado) - Universidade Federal da Bahia, Faculdade de Comunicação, Salvador, 2010.

SILVA, Kalina Vanderlei e SILVA, Maciel Henrique. Dicionário de conceitos históricos. 2. ed. São Paulo: Contexto, 2006.

Submetido em: 2-6-2020

Aceito em: 21-5-2021 